\title{
I CAN'T DO EVERYTHING! COMPETING PRIORITIES AS CONSTRAINTS IN TRIATHLON EVENT TRAVEL CAREERS
}

\author{
MATTHEW LAMONT* and MILLICENT KENNELLY†
}

*School of Tourism and Hospitality Management, Southern Cross University, Lismore, NSW, Australia $\dagger$ Department of Tourism, Leisure, Hotel and Sport Management, Griffith University, QLD, Australia

\begin{abstract}
The term "event travel career" describes how highly involved and/or committed persons pursue a career of travel to organized events linked to their preferred leisure activity. The introduction of this significant, discretionary social role may lead to individuals experiencing dilemmas in prioritizing between day-to-day needs and desires and those of their event travel career. This article discusses how the concepts of competing priorities and opportunity costs are useful in understanding constraints faced by serious leisurists pursuing an event travel career. The sport of triathlon was chosen as a context in which to examine these concepts. A textual analysis of postings to an Australian online forum for triathletes was undertaken over 4 weeks. The data supported the contention that persons who train for and travel to triathlon events face significant resource-related constraints in the form of competing priorities. Three domains where the triathletes encountered competing priorities in their lives were identified: intrapersonal, interpersonal, and structural. In terms of negotiating constraints presented by their competing priorities, the triathletes appeared willing to accept a range of opportunity costs in order to maintain momentum in their event travel career. This study contributes to enhancing knowledge regarding constraints faced by serious leisurists in a tourism context, and also in understanding the broader implications of constraints negotiation at the individual level.
\end{abstract}

Key words: Constraints; Competing priorities; Opportunity costs; Serious leisure; Event travel career

\section{Introduction}

Jackson (1988) defines leisure constraints as circumstances that "inhibit people's ability to participate in leisure activities, to spend more time doing so, to take advantage of leisure services, or to achieve a desired level of satisfaction" (p. 203). While an extensive body of knowledge exists addressing the nature of constraints faced by leisure participants and the strategies employed in overcoming constraints, application of leisure constraints theory in tourism research is sparse (Wilson \& Little, 2005). Furthermore, there has been little exploration of constraints faced by those engaged in serious leisure (Stebbins, 1982). There has also been very little consideration of the constraints encountered by those who travel to participate in serious leisure. This article contributes to 
the leisure constraints literature by exploring the utility of competing priorities as a means of understanding resource-related constraints faced by persons pursuing what Getz $(2007,2008)$ described as an "event travel career" linked with sport.

For the purposes of this article, the term competing priorities refers to a clash between an individual's needs and desires of a day-to-day nature (such as maintaining happy relationships with friends and family, being able to satisfy financial obligations, fulfilling domestic responsibilities, etc.), against needs and desires relating to their event travel career (e.g., being able to fund travel to events, accessing sufficient leisure time to physically prepare for attendance at events, purchase necessary equipment, etc.). Non-elite triathlon participants are used to explore resource-related constraints to ongoing participation in leisure among highly involved participants. It is argued that resource-related constraints manifest in the form of competing priorities when an individual introduces an additional, discretionary social element into their life, such as an event travel career. Qualitative evidence gathered from an Internet forum for triathletes is presented to demonstrate the usefulness of competing priorities in understanding the complex web of constraints faced by those who intensively participate in leisure.

\section{Literature Review}

\section{Leisure Constraints and Constraints Negotiation}

Leisure constraints can both inhibit participation in a leisure activity or influence the extent to which an individual can participate in, and derive satisfaction from, leisure activities (Jackson, 1988). Wilson and Little (2005) noted that early research into leisure constraints centered on barriers that prevent people from participating in leisure activities. However, recent research has tended to focus on how constraints are negotiated to enable an individual to maintain or increase participation in an activity (Gilbert \& Hudson, 2000).

A seminal conceptualization of leisure constraints was presented by Crawford and Godbey (1987). These authors conceptualized leisure constraints as social-psychological barriers that influence leisure preferences and behavior. Three dimensions make up Crawford and Godbey's (1987) leisure constraints model. Intrapersonal constraints are intrinsic states and attributes that limit participation, such as fear, anxiety, stress, or a lack of perceived skill. Interpersonal constraints stem from interpersonal interactions and commonly arise as a result of spousal interaction. For example, choice of leisure activity may be determined by joint preference. However, the notion of interpersonal constraints is pertinent to interpersonal relations generally (Crawford, Jackson, \& Godbey, 1991). Therefore, inability to locate a suitable training partner is also an example of an interpersonal constraint. Finally, structural constraints are conditions that intervene between leisure preference and participation, such as limited time and money.

In a revised version of this framework, Crawford et al. (1991) suggested that intrapersonal, interpersonal, and structural constraints should be thought of in a hierarchical manner. They viewed leisure participation as being dependent upon sequentially negotiating these layers of constraints. Intrapersonal constraints were therefore posited as the most powerful constraints, and must be overcome before the individual will face interpersonal constraints. Interpersonal constraints need to be negotiated before the individual faces structural constraints. Some authors have presented evidence supporting this hierarchical nature of constraints. For example, in their study of US citizens, Samdahl and Jekubovich (1997) found that intrapersonal constraints hampered the development of friendships, while interpersonal constraints prevented participation in some leisure activities because of a lack of social support. However, the same study also presented evidence suggesting Crawford et al.'s hierarchy of constraints is not absolute.

Until the early 1990s, leisure constraints were regarded as insurmountable barriers preventing participation. Jackson, Crawford, and Godbey (1993) questioned this notion and suggested that negotiation of constraints is much more common than nonparticipation. Constraints negotiation researchers have subsequently tended to use participation as an indicator of success (Wilson \& Little, 2005). That is, if an individual reaches a point where they participate, it is assumed that all constraints have been successfully negotiated. As 
such, there are gaps in the literature in understanding how people maintain leisure participation at their desired level. It may well be the case that highly involved leisure participants are willing to accept sacrifices or make tradeoffs in some aspects of their life in order to overcome constraints and achieve their leisure goals. The notions of sacrifices, tradeoffs, and prioritization have been raised previously by numerous authors as strategies for negotiating leisure constraints (e.g., Jackson et al., 1993; Little, 2002). Indeed, Jackson et al. (1993) suggested that:

it may even be speculated that the confrontation and successful negotiation of leisure constraints can enhance participation as people rearrange their schedules, spending priorities, and other aspects of their lives to accomplish their leisure-related goals. (p. 5)

Jackson et al. (1993) also noted that "the economic concept of opportunity cost applied to leisure participation is an implicit statement of the tradeoffs that must be made in the face of financial constraints" (p. 7). It is arguable, however, that in the context of constraints negotiation, opportunity costs are not strictly economic. They may manifest in other facets of peoples' lives. For example, amateur athletes who are highly driven and have strong affective attachment to their leisure goals may forgo spending leisure time with friends and family to free up time to physically prepare for upcoming events (e.g., see Atkinson, 2008). Therefore, there is a need to consider level of intensity of participation when seeking to understand constraints due to complexities that may arise when participation in leisure increases over what may be considered "normal" levels of participation.

\section{Event Travel Careers and Serious Leisure}

Special events are an important stimulus for tourism, and many destinations have turned to events as a means of economic and social development. Despite the clear link between special events and tourism, event tourism has only recently begun to attract attention by scholars (Getz, 2008). Event tourism remains an underresearched area, which has implications for sustainable growth and the advancement of theory in this field.
One aspect of event tourism in which "researchers have so far only scratched the surface" (Getz, 2007, p. 241) is the concept of event travel careers. The concept of an event travel career (ETC) is an adaptation by Getz (2007) of Pearce's (2005) travel career ladder. Pearce suggested that as a traveler becomes more experienced, their motivations will shift from lower order motives, such as relaxation and safety, to higher order motives, such as fulfillment, as the individual travels more and progresses in their travel career. Getz's (2007, 2008) idea of an ETC is similar. It suggests that persons who exhibit high levels of involvement in or commitment to a leisure activity can initiate a career of traveling to events, characterized by a progression in the benefits and challenges sought.

Getz's ETC concept is further underpinned by Stebbins' (1982) theory of serious leisure, described as "the systematic pursuit of an amateur, hobbyist, or volunteer activity that is sufficiently substantial and interesting for a participant to find a career there in acquisition and expression of its special skills and knowledge" (Stebbins, 2001, p. 3). Six qualities proposed by Stebbins (2001) are associated with engagement in serious leisure. Serious leisurists will persevere and may need to negotiate constraints to maintain participation in their chosen leisure activity. Serious leisure can spark the initiation and development of a career pursuing a leisure activity, characterized by progression and stages of achievement. Significant time and personal effort is often invested to acquire knowledge or skills related to the leisure activity, of which the individual may experience durable benefits including feelings of accomplishment and self-gratification. Individuals may develop a strong social identity through their leisure activity, and lastly, there may be entry into the unique social world surrounding that activity. ETCs are promulgated by Getz (2008) as typically being the realm of highly committed and highly involved persons - that is, those who partake in serious leisure.

Getz (2008) proposed five characteristics of an ETC. These include intrinsic motivation within an individual to travel to events, and progression in the events traveled to and benefits sought (in active sport tourism ETCs this progression could manifest in the form of travel to events that present increased levels of challenge). A further ele- 
ment of progression should be evident with reference to the geographic scope of travel to events over time (e.g., progressing from local events through to overseas travel to participate in events). ETCs are also characterized by an evolution in individuals' preferences relating to event characteristics (e.g., traveling to more prestigious events over time). Finally, ETCs are characterized by modifications in behavior, such as combining holidays with travel to events.

While Getz (2008) did not explicitly mention the role of constraints in characterizing ETCs, perseverance and overcoming constraints is acknowledged as a quality of serious leisure (Stebbins, 2001). Given the discretionary nature of pursuing an ETC, personal willingness to negotiate constraints that hinder the pursuit of an ETC at the desired level should be an addition to the criteria described above, especially because serious leisure forms part of the theoretical underpinning for the ETC concept.

\section{Competing Priorities as Constraints in Triathlon Event Travel Careers}

Pursuing an ETC involves a high level of commitment and involvement by participants towards their chosen leisure activity (Getz, 2007, 2008). Consequently, those pursuing an ETC may experience constraints, particularly in instances where the ETC is linked with sport:

participation in sport tourism activities is influenced by constraints. The potential for modifying these constraints requires a fuller understanding of the process and conditions under which these constraints influence sport tourism behavior. (Hinch, Jackson, Hudson, \& Walker, 2005, p. 147)

The issue of limited resources is a common theme within the literature as a factor that can constrain leisure participation. Resources are defined as "things within an individual's control that can be used to resolve the demands placed on him or her" (Robbins, Judge, Millett, \& Waters-Marsh, 2008, p. 698). Given the additional demand on an individual's resources that arise by virtue of an ETC, it is argued that the initiation and continuity of an ETC is constrained by an individual's resources. Further, an individual's resources have al- ternative uses, often at odds with one another. Negotiating resource-related constraints therefore requires the individual to make decisions in allocating resources either to support their ETC, or to support other needs or desires in their life. Consequently, it may be difficult for people to fulfill the entire spectrum of their day-to-day needs and desires, while simultaneously pursuing an ETC at their desired level. As an individual's day-to-day needs and desires can clash with those of their ETC, they may need to accept opportunity costs, or the loss of benefits that may have eventuated if one course of action was prioritized over another. For the purposes of this article, this clash of needs and desires is referred to as "competing priorities."

This article uses the sport of triathlon as a context in which to investigate competing priorities. Opportunities exist for participants to engage in a career of traveling to triathlon events throughout the world. Furthermore, there is a distinct hierarchy of events in terms of duration, challenge, and prestige (McCarville, 2007). As such, the global calendar of events, combined with broad scope for progression, means that triathlon is a leisure activity that provides a relevant context in which to study ETCs. This article addresses non-elite triathletes, referring to persons who participate in triathlon events on an unpaid basis as distinct from professional athletes. Non-elite triathlon competitors are henceforth referred to as "triathletes."

The purpose of this article is therefore to illustrate that an individual's competing priorities, in combination with limited resources, can constrain the pursuit of an ETC. Although this notion is acknowledged to some extent within the leisure constraints literature, the role of opportunity costs in the constraints negotiation process and the impact on people's lives of opportunity costs arising from the negotiation of competing priorities, are underemphasized. These issues are also yet to be explored in the context of ETCs linked with sport.

\section{Methods}

This exploratory project adopted an interpretive approach to data collection and analysis. As little has been written regarding competing priorities in the context of ETCs, qualitative methods were deemed appropriate for this study because of their 
ability to generate rich, detailed descriptions of the phenomenon under investigation (Veal, 2006). Rich textual data were gathered for use in subsequent theory generation (Creswell, 2003). Through this approach the researchers sought to explore the competing priorities that triathletes encounter, which influence their pursuit of an ETC. The outcomes of exploratory research of this nature can then serve as a platform for future research (Neuman, 2006).

This research incorporated the collection of secondary data. Textual data were collected from an Internet forum for triathletes, where thread discussions were monitored over a 4-week period. This forum is utilized mostly by non-elite triathlon participants, although professional (paid) triathletes are not prohibited from participating. Discussions typically address issues surrounding equipment, training, and race reports/news. In particular, discussions pertaining to conflict between the pursuit of ETC goals and day-to-day needs and desires were monitored. The forum participants tended to speak openly about their involvement in triathlon and how it integrates into their lives.

However, data collected from online sources such as forum communities can lack context (Kozinets, 2002). Therefore, a criticism of this Internet forum as a source of data relating to ETCs may be that thread discussions tend to center on participants' day-to-day involvement in triathlon and that the travel element of the ETC is not adequately captured. However, there were two key reasons why this Internet forum was considered a useful data source for this exploratory study. Firstly, there was evidence within the discussions of participants traveling to, or planning to travel to compete in triathlons. Opportunities to compete in triathlon events are often limited by tight supply (e.g., see USM Events 2010; World Triathlon Corporation, 2010), and depending upon an individual's geographic location, it is usually necessary to travel away from the home region to compete. Secondly, it is argued an ETC in triathlon is embedded within these triathletes' daily lives. Consistent with observations made by Atkinson (2008) and McCarville (2007), many of the triathletes' comments indicate that they engaged in daily physical training to prepare for events they ultimately travel to. Thus, day-to-day involvement in triathlon-related activities (such as regular training sessions) is a crucial underpinning of an ETC. The Internet forum was therefore considered an appropriate source of data for the present study.

All thread topics posted to the forum 2 weeks either side of the date of a major Ironman triathlon event on the international triathlon calendar were monitored. Ironman triathlons involve a $3.8 \mathrm{~km}$ swim, $180 \mathrm{~km}$ cycle, and $42.2 \mathrm{~km}$ run and require a great deal of time and commitment to prepare for. Data collection was timed around this event as it is common in the lead-up to major events for forum participants to discuss their training and how it integrates into their lives. Any postings (part or whole) that alluded to competing priorities encountered in the process of preparing for an event, during an event, and after an event were extracted for analysis.

Data collected were subjected to a textual analysis, a qualitative subset of the broader family of techniques known as content analysis, which Neuman (2006) described as a means of "gathering and analysing the content of text" (p. 322). Textual analysis differs from other content analysis techniques, in that this approach does not attempt to understand the meaning of written material through quantitative measurement or through the application of predetermined codes (Jennings, 2001). Given the exploratory nature of this study, textual analysis was deemed appropriate as it allowed for themes to emerge from the data.

Blocks of text extracted from thread postings were analyzed using a three-stage process consisting of open, axial, and selective coding as described by Neuman (2006). The deeper analysis associated with selective coding was hampered, however, as the anonymous nature of the data limited the researchers' abilities to make betweengroup comparisons. To improve intercoder reliability, two researchers performed open and axial coding processes independently, and then compared the outcomes before selective coding was undertaken.

\section{Findings}

Three dominant themes relating to constraints presented by competing priorities were identified. Each theme pertained to an area of life, or "do- 
main," in which the triathletes appeared to experience competing priorities (i.e., conflict between day-to-day needs and desires, and those relating to their ETC). In attempting to overcome the constraints presented by these competing priorities, it was evident that the triathletes commonly made decisions within these three domains that resulted in opportunity costs, or situations where resources were allocated either in favor of their ETC at the expense of their day-to-day needs and desires or vice versa. Broadly, these three domains were 1) personal preferences relating to leisure participation where the individual could control decisions, such as diet and choice of leisure activities; 2) personal relationships, such as family and social relationships; and 3) aspects of the individual's life where external variables affected leisure participation, such as limited time and money.

In labeling the three emergent domains of competing priorities, Crawford and Godbey's (1987) categories of leisure participation barriers were adopted: intrapersonal, intrapersonal, and structural. This research did not explicitly set out to test Crawford and Godbey's model. However, that the themes emerged from the data in this way is a testament to the robustness of their contribution. The findings relating to the intrapersonal, interpersonal, and structural domains of competing priorities are now presented and discussed.

\section{Intrapersonal Competing Priorities}

Intrapersonal competing priorities occur where the individual has complete or almost complete control over how much influence a factor affects their pursuit of an ETC. Competing priorities within the intrapersonal domain included diet, leisure activities, and personal health.

Figure 1 illustrates the intrapersonal competing priorities that emerged from the data. The lefthand hemisphere represents day-to-day needs and desires, while the right-hand (shaded) hemisphere illustrates opposing needs and desires, which relate to the ETC. The same convention is used in Figures 2 and 3. As argued earlier, a core proposition within this article is that resource-related constraints presented by competing priorities will most commonly be negotiated by prioritizing the allocation of limited resources between satisfying

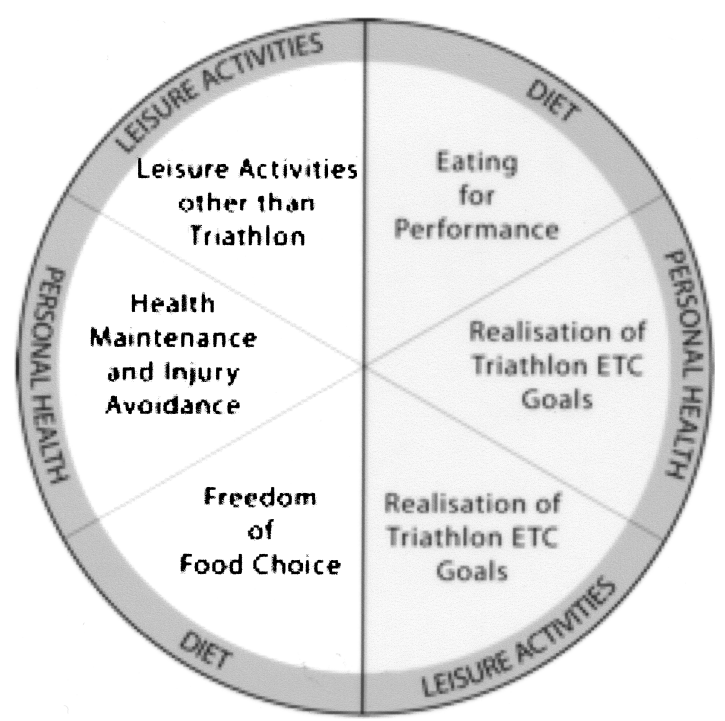

Figure 1. Intrapersonal competing priorities experienced by non-elite triathlon participants (adapted from Quinn, Faerman, Thompson, McGrath, \& St. Clair, 2007, p. 16).

day-to-day needs and desires versus those relating to the ETC. The data supported the notion that the outcome of this process is often an opportunity cost, where one set of needs and desires is satisfied at the expense of another.

An intrapersonal competing priority commonly mentioned was labeled "dietary preferences." Excess body weight and the consumption of particular foods and beverages were viewed as being detrimental to sporting performance. Therefore, the triathletes described grappling with competing priorities involving freedom of choice in the food they eat (particularly in social situations involving non-triathlon friends and family) against their desire to minimize body weight in order to maximize athletic performance. The data indicated that the triathletes tended to make sacrifices by restricting intake of certain foods during the preparation phase for important events. However, once an event had passed, this restriction appeared to ease, as described by Triathlete C:

[after the event] eat lots of crap food, go to the pub, eat a 700g steak and wash it down with the cheese platter for two for one. Give it about four weeks and then start planning the next [triathlon]. 
Similarly, Triathlete F prescribed "a box of Froot Loops" as a treat, following dietary restrictions leading into competition:

hadn't eaten them since I was a kid, they taste awesome. Everyone should buy some now.

Choice of leisure activities was another area of competing priorities. Triathlon is a combination of three separate sports and consistent, extensive effort is required to gain and maintain fitness in all three. The data suggested that extensive time and energy is required to improve performance in swimming, cycling, and running, which consequently appeared to restrict the triathletes' ability to participate in other leisure activities. For example, in a discussion thread following an Ironman distance event, one triathlete explained that they were looking forward to engaging in leisure activities other than swimming, cycling and running during their recovery period:

I thought I was coping with it but am feeling exhausted and mentally flat after finding out that I am a good 2 hours short of where I need to be. Anyhow I have found that a 9 hour drinking session watching premier league soccer ... with the lads who don't care about triathlon normally perks me up, will be hitting the turps at $3 \mathrm{pm}$ tomorrow. (Triathlete $\mathrm{H}$ )

The final category of intrapersonal competing priorities was labeled "personal health." This was a strong theme identified in the data, suggesting that the triathletes frequently grapple with maintaining their personal health and remaining free of injury, against their desire to achieve their triathlon ETC goals. Many triathletes spoke of pushing their physical limits, knowing that they may physically damage their body in order to achieve "personal best" performances. Some even reported engaging in competition while ill, to take part in the Ironman World Championships-considered the pinnacle of the sport amongst non-elite triathletes:

[I] carried a virus into the race [Ironman World Championships], lost 16.8 pounds out on the course and spent a few hours in the medical tent at $\mathrm{T} 2$... . Agree with [name A] about needing to be $100 \%$ for this race. Had blood in the urine for a few days afterward, and only now 6 months later am I confident enough to push hard again. Wouldn't swap any of these experiences for anything and hope to go back in 2011 in a new age group. (Triathlete G)

While the triathletes faced a range of internal competing priorities unique to their individual circumstances, their ability to pursue an ETC was further constrained by their desire to maintain relationships with those around them. These were categorized as "interpersonal" competing priorities and the findings pertinent to this theme are presented in the ensuing section.

\section{Interpersonal Competing Priorities}

Interpersonal competing priorities identified in this study were constraints brought about as a result of the triathletes' relationships with other people. These competing priorities related mostly to their spousal relationship, family, and social relationships (see Fig. 2). This finding was consistent with the definition of interpersonal constraints offered by Crawford and Godbey (1987).

The impacts of pursuing an ETC on the triathletes' relationships with their spouse and family were particularly common themes. Some comments suggested the role of the spouse as being a consent

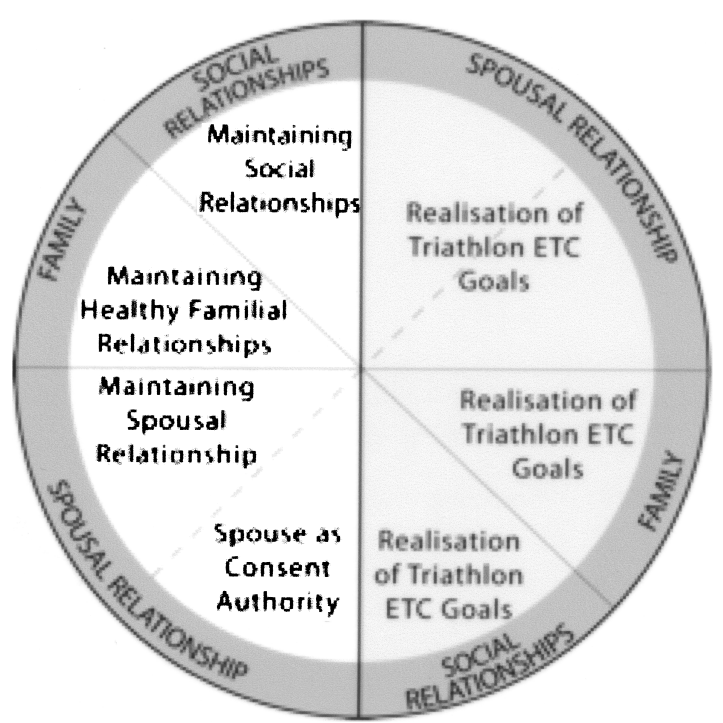

Figure 2. Interpersonal competing priorities experienced by non-elite triathlon participants (adapted from Quinn et al., 2007, p. 16). 
authority. For example, one triathlete made the following comment about his decision to sign up for his first Ironman:

I just got approval from the Mrs-I am in. (Triathlete C)

The data revealed not only the potential influence of the spouse on the trajectory and intensity of participation in an ETC, but also uncovered the potential strain that can be placed on the spousal relationship by pursuing an ETC:

I just ducked down to see her during lunch [my wife]. She isn't coming. Don't get me wrongshe is $200 \%$ supportive day to day. I spend ridiculous amounts of money on this stuff-plus all of the time, race entry fees, travel, etc. Just doesn't want to drive 7 hours, be ignored overnight and hang around with 5 minute glimpses of me-in order to be supportive when I finish and collapse. (Triathlete $\mathrm{J}$ )

Competing priorities were also evident in relation to the triathletes' familial relationships. Comments posted after an Ironman triathlon revealed the triathletes' realization of the sacrifices that family members had made to enable them to pursue their ETC. Indeed, one triathlete was conscious of the tolerance of his family:

The ThankYou's: My wife and kids [emphasis in original]. For putting up with my obsession and giving me the necessary wake up to yourself call(s) when needed. (Triathlete $\mathrm{M}$ )

Numerous other comments alluded to the significance of family support. This was a competing priority in that some triathletes described facing tension in allocating considerable quantities of leisure time pursuing an ETC that might otherwise be spent with family, while simultaneously expressing the importance of family support and tolerance:

When I went past the Breakwall heading to the south turn around I saw the wife and kids, [my daughter] was crying and she wanted a hug, it was a big day for them all, up early to watch their dad do something that he trained for selfishly for the last 12 months. (Triathlete L)
In addition to the strain placed on spousal and familial relationships by pursuing an ETC, social relationships with friends were also affected by the relentless physical training regimes and travel itineraries adhered to by these triathletes. The following quotes, which were made in the aftermath of an Ironman event suggest that social relationships, particularly with friends who do not share an interest in triathlon, were largely cast aside during preparation phases for important events:

I am also one that doesn't have family in the area/state or a partner. The long weekend will be spent sleeping, chilling, watching TV, catching up with neglected friends, eating way too much of the wrong things. (Triathlete $\mathrm{M}$ )

Are there friends and family that you haven't seen in a while? Take the opportunity to socialise now. Don't overdo it on the grog but certainly have a beer or wine or two in the evening. Organise a small dinner or lunch outing or get together with a few people. Things that you haven't been able to do, or have restricted yourself from doing, while training. (Triathlete C)

Moreover, the triathletes' abilities to pursue an ETC were further stretched by extraneous variables beyond personal preferences and relationships. "Structural" competing priorities also exerted a significant constraining influence, and are discussed in the next section.

\section{Structural Competing Priorities}

The final domain of competing priorities identified in the data was related to external variables that intervene with leisure participation and preferences (Crawford \& Godbey, 1987). Figure 3 illustrates that structural competing priorities faced by the triathletes in pursuing an ETC included career, finances, and domestic responsibilities.

Tension appeared to exist between the triathletes' careers and their ETC. The following two quotes suggest that some experienced dilemmas in prioritizing time and energy between the competing priorities of work and their ETC. Triathlete A explained:

I am inherently lazy at everything other than training and find work a tiresome interruption to my daily schedule. 


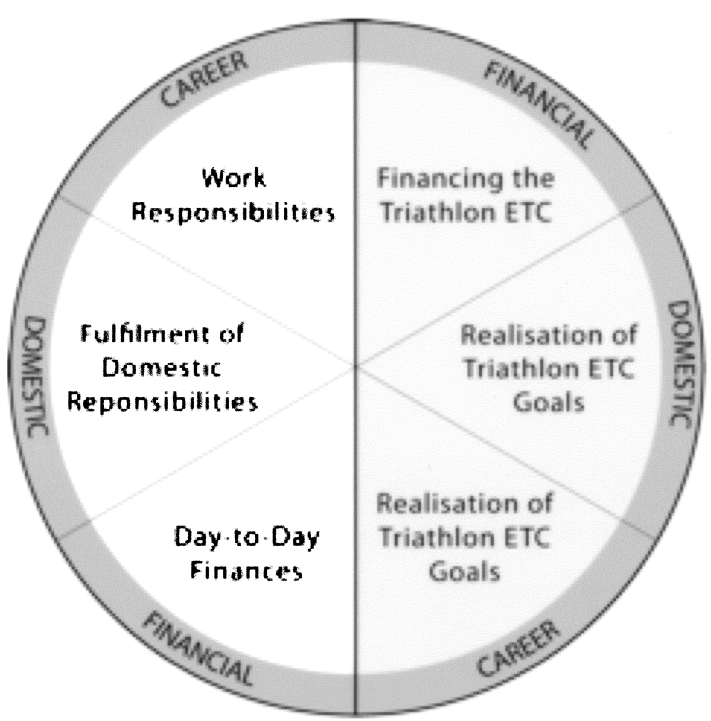

Figure 3. Structural competing priorities experienced by non-elite triathlon participants (adapted from Quinn et al., 2007, p. 16).

Another mentioned long work hours as a constraint in realising ETC goals:

Having seen someone like [name B] get there changed my mind. In his first IM he did 13:3x [approximately 13 and a half hours] (from memory). That was in 2001. In 2009 he qualified and got to Kona. [name C] himself after many years trying also qualified... [he] mentioned to me that he hasn't slept past 4:30am in over 3 years. ... He also works long hours. Has 2 kids. I think [name D] has 3 or 4 kids. If you aren't willing to do what these guys have, then maybe you should walk away, cause your dream isn't going to come true. (Triathlete D)

Money was a finite resource that invoked a range of competing priorities for the triathletes. Some indicated that they were strategic in selecting the events they travel to in order to minimize the cost of participation:

OK, tossing up which one to do. Did GC [Gold Coast Half Ironman] last year so in a way I'd like to go back and see how I've hopefully improved. But I hear Yep [Yeppoon Half Ironman] is a great race. Not really worried about road or run surface quality but a bit of atmosphere around the event would be cool. I'm on a budget so at the
GC I sleep in the back of my van; are there any camping facilities near Yeppoon? And is Yep a wetty [wetsuit] race, as I don't own one and won't be owning one so if there's a chance it's a wetsuit compulsory race then that would cancel it out. (Triathlete F)

Other triathletes harbored desires of owning advanced equipment, hoping they could "buy" faster times. At times, however, purchasing expensive equipment was frowned upon by their spouse (as alluded to in the previous section on interpersonal competing priorities). Some triathletes described strategies aimed at convincing their spouse to approve ETC related purchases:

I have been trying to figure out how much benefit a TT [time trial bike] would be to me over the distance but have only performed on the roadie. It will be good to get others real life comparisons for my case to the finance minister for next season! To note, after seeing the blinged out TT bikes on the weekend I want one, even just for show! (Triathlete G)

my wife insists I have too many bikes, however the logic I use is that once you have them they are virtually worthless if you try and re sell them. (Triathlete $\mathrm{H}$ )

The eternal hope of qualifying for an entry slot in the "holy grail" of triathlon events, the Ironman World Championships (or "Kona" as it is commonly known, referring to the event's location, Kailua Kona, Hawaii) compounded the constraints presented by financial competing priorities. Competitors must qualify for the Ironman World Championships by achieving a fast result at one of the global qualifier events. As the following quote illustrates, triathletes may travel overseas to participate in qualifier events, hoping that competition may be of a lower standard than in their home country:

most people who've not qualified for Kona after years trying at Australian races just go overseas and qualify at an easier to qualify at race. (Triathlete $\mathrm{J}$ )

Finally, a competing priority existed in relation to the triathletes' domestic obligations versus their desire to devote time and energy to pursuing their 
ETC. Themes here included the neglect of domestic responsibilities (such as house chores) and also neglecting parental responsibilities in favor of pursuing ETC aspirations, as the following quotes illustrate:

[After the race] give your body time to rebuild and recover. Time to chill out and enjoy the company of your family and friends. Get some jobs done that you had put on the back burner. Give your heart, mind and body some well deserved time out!! (Triathlete C)

doing Ironman isn't just one person getting over the line, it's those countless hours where others make sacrifices to help their aspiring Ironman train and prepare for the race. Without them, I couldn't have done it. (Triathlete L)

\section{Discussion and Conclusions}

The purpose of this article was to demonstrate that the concept of competing priorities is useful for understanding constraints to ongoing participation in serious leisure, and in understanding how serious leisurists pursuing an ETC negotiate constraints. Non-elite triathletes pursuing an event travel career were used as a context to undertake this exploratory research. Building upon the assertions of previous authors (e.g., Jackson et al., 1993; Little, 2002) that acceptance of opportunity costs is a means of overcoming resource-related constraints, it was argued that serious leisure participants such as those pursuing an ETC have both day-to-day needs and desires, as well as needs and desires relating to their ETC. In light of limited resources, pursuing an ETC may necessitate prioritization of day-to-day needs and desires against those relating to the ETC. The outcome of this prioritization of resources is most likely to be an opportunity cost.

This research supported the contention outlined above. The triathletes studied encountered a range of competing priorities that constrained them in pursuing an ETC in triathlon at their desired level of intensity. These competing priorities were classified as intrapersonal, interpersonal, and structural, in accordance with Crawford and Godbey's (1987) model of leisure constraints. This research used an inductive logic and therefore did not attempt to filter the data through Crawford and God- bey's framework. Rather, their labels were adopted due to the similarities between the themes identified in the data and the nature of Crawford and Godbey's categories.

Earlier literature on leisure constraints postulated constraints as barriers to participation (Crawford \& Godbey, 1987; Jackson, 1988, Scott \& Jackson, 1996). However, this study found that the triathletes instead faced barriers in terms of achieving their ETC goals. As such, it is not barriers to participation that are the issue here. Instead, it is constraints to pursuing the ETC on an ongoing basis, and at a desired level of intensity that were more prevalent. This finding supports Crawford et al.'s (1991) position that constraints do not necessarily prevent participation, but instead influence the degree of intensity of participation. Although a causal relationship cannot be proven with the data available, the present study suggests that if affective attachment to a leisure activity is strong enough, serious leisure participants are prepared to accept significant opportunity costs to enable ongoing participation. The triathletes' liberal allocation of resources in favor of their ETC is reflective of the lengths serious leisurists may go to in overcoming the competing priorities encountered. Examples of such included the triathletes' willingness to forgo leisure time with their family and friends, and abstinence from leisure activities beyond swimming, cycling, and running. These examples also support Jackson et al.'s (1993) idea that leisure participation can be enhanced by rearranging parts of one's lifestyle to achieve leisure goals.

A further contribution made by this study is the cyclical nature of competing priorities encountered by those pursuing an ETC. Samdahl and Jekubovich (1997) asserted that "constraints are not static and stationary" (p. 432), and the data collected in this study suggested that resource demands in pursuing an ETC are characterized by peaks and troughs. In the months leading up to a major event, the triathletes' lifestyle choices seemed more directed at minimizing constraints that may hamper their ability to prepare for, travel to, and perform well at an event. Upon return from the event, ETC needs and desires seemed to decrease in priority as the triathletes took action to compensate for their neglect of day-to-day needs 
and desires during the preparation phase. Examples of this compensatory behavior included concerted efforts to spend time with friends and family, and indulging in foods that were restricted or eliminated during preparation for an event.

Hubbard and Mannell (2001) have previously demonstrated that encountering constraints triggers negotiation strategies to reduce or mitigate their negative effects on participation. They also suggested that the greater a person's motivation to participate in leisure, the greater their efforts to negotiate constraints were likely to be. Hubbard and Mannell's findings could partly explain the cyclical nature of competing priority constraints observed in the present study. That is, motivation to participate in leisure could increase during the build-up to an event, meaning opportunity costs are more willingly accepted during this phase to minimize the constraining influence of competing priorities. Further research is needed to better understand the cyclical nature of constraints negotiation strategies. Such research might also assess whether this condition is unique to those engaged in an ETC linked with endurance sports.

The impacts of pursuing an ETC on the triathletes' relationships with their spouse and family were particularly evident. Some comments suggested the role of the spouse as a consent authority. As such, the spouse may directly or indirectly regulate the level of intensity at which at an ETC can be pursued. The spouse may be viewed as having power to impose constraints, and/or ameliorate perceived constraints (e.g., when a triathlete feels obligated to ask their spouse's permission to make a significant purchase).

Other comments alluded to the strain on familial relationships caused by the resource-intensive nature of a triathlon ETC. The vast financial and leisure time demands associated with preparing for and traveling to triathlon events impacted upon the triathletes' families positively and negatively. Indeed, the data supported McCarville's (2007) suggestion that participation in triathlon events can "virtually dominate the lives of participants and their families" (p. 160). This research revealed numerous negative impacts on familial relationships brought about by the triathletes' acceptance of opportunity costs in overcoming competing priorities that constrained their pursuit of an ETC. Subse- quently, it is clear that research into constraints negotiation should go beyond the individual level and consider the broader systemic implications of constraint negotiation strategies, particularly the acceptance of opportunity costs, on serious leisure participants' familial and social networks and career.

A number of issues to do with the structural domain of competing priorities also warrant discussion. From the data, career did not emerge as a strong theme. However, the competing priorities of fulfilling work obligations versus pursuing an ETC in triathlon appeared fraught with tension due to the vast resources that both require in order to achieve success. As one triathlete noted, work was an inconvenient interruption to pursuing their ETC. Comments to this effect imply very high levels of affective attachment to the leisure activity, which has been previously observed by some authors (e.g., Atkinson, 2008; McCarville, 2007). As the data suggested, extreme time pressure and other strains on personal resources can arise when extravagant leisure goals are pursued, which for most people are then exacerbated by the need to work. Therefore, those pursuing an ETC in endurance sports arguably face unique challenges in apportioning their resources. Not only could work/ life balance be an issue, so too could leisure/life balance due to the demands of these concurrent careers.

Two further issues vex the understanding of career versus an ETC as competing priorities. The first issue is conditions of employment. These dictate the scheduling of work time and availability and access to leave, which can subsequently influence the pursuit of an ETC. Some will have a degree of control over their work schedule (e.g., the self-employed) while others have less control (e.g., shift workers). As such, the control an individual has over their work hours could be an important variable influencing one's ability to pursue an ETC. Furthermore, casual workers may not have access to paid annual leave, imposing additional constraints. Workers with paid annual leave entitlements may face competing priorities in terms of budgeting leave between traveling to events, balanced against allocating leave to other leisure that may be of higher salience to their family unit. The second issue is the prioritization be- 
tween career aspirations and ETC aspirations. Research is needed to explore how career aspirations constrain the pursuit of an ETC aspirations, and vice versa. Research along these lines might also consider the influence of mediating variables such as motivations, individual value systems, or personality type in this decision-making process.

In addition to the avenues for future research already mentioned, numerous other opportunities exist to apply the concepts of competing priorities and opportunity costs in studying leisure constraints. Further research is needed to identify and understand the full range of competing priorities and opportunity costs pertinent to those pursuing an ETC, not only in triathlon, but also other sports. The ideas presented in this article could also be extended beyond the realm of ETCs linked with sport, to include ETCs associated with musical, artistic or cultural events.

The limitations of the methods used in this study should be acknowledged as these limitations present opportunities for future research. Firstly, information posted on the Internet forum did not reveal the triathletes' marital status, nor if they had children. This made it difficult to assess the full extent to which interpersonal competing priorities influenced the pursuit of an ETC. There is a need to collect primary empirical data to validate the conclusions made in this article, and also to identify latent competing priorities that this methodology was incapable of uncovering.

Finally, while there was evidence within the data of the triathletes traveling to, or planning to travel to, compete in events, it was not possible to verify the intensity of the forum participants' pursuit of an ETC. The anonymous and secondary nature of the data precluded the researchers from establishing whether the triathletes had sought progression in the events they have participated in over time, which is a key element of ETCs according to Getz (2007, 2008). Although the data were considered appropriate for this exploratory study, future research employing qualitative methods such as in-depth interviews or focus groups would be of value in overcoming the methodological limitations of this study.

\section{Acknowledgments}

The authors would like to acknowledge funding assistance for this project provided by the Division of Research, Southern Cross University. The two anonymous reviewers are also thanked for their comments which assisted in strengthening the original manuscript.

\section{References}

Atkinson, M. (2008). Triathlon, suffering and exciting significance. Leisure Studies, 27(2), 165-180.

Crawford, D., \& Godbey, G. (1987). Reconceptualizing barriers to family leisure. Leisure Sciences, 9(2), 119127.

Crawford, D., Jackson, E., \& Godbey, G. (1991). A hierarchical model of leisure constraints. Leisure Sciences, 13(4), 309-320.

Creswell, J. (2003). Research design: Qualitative, quantitative, and mixed methods approaches (2nd ed.). Thousand Oaks, CA: Sage.

Getz, D. (2007). Event studies: Theory, research and policy for planned events. Oxford: Butterworth-Heinemann.

Getz, D. (2008). Event tourism: Definition, evolution, and research. Tourism Management, 29(3), 403-428.

Gilbert, D., \& Hudson, S. (2000). Tourism demand constraints: A skiing perspective. Annals of Tourism Research, 27(4), 906-925.

Hinch, T., Jackson, E., Hudson, S., \& Walker, G. (2005). Leisure constraint theory and sport tourism. Sport in Society, 8(2), 142-163.

Hubbard, J., \& Mannell, R. (2001). Testing competing models of the leisure constraint negotiation process in a corporate employee recreation setting. Leisure Sciences, 23(3), 145-163.

Jackson, E. (1988). Leisure constraints: A survey of past research. Leisure Sciences, 10(2), 203-215.

Jackson, E., Crawford, D., \& Godbey, G. (1993). Negotiation of leisure constraints. Leisure Sciences, 15(1), $1-11$.

Jennings, G. (2001). Tourism research. Milton, Australia: John Wiley \& Sons.

Kozinets, R. (2002). The field behind the screen: Using netnography for marketing research in online communities. Journal of Marketing Research, 39(1), 61-72.

Little, D. (2002). Women and adventure recreation: Reconstructing leisure constraints and adventure experiences to negotiate continuing participation. Journal of Leisure Research, 34(2), 157-177.

McCarville, R. (2007). From a fall in the mall to a run in the sun: One journey to Ironman triathlon. Leisure Sciences, 29(2), 159-173.

Neuman, W. L. (2006). Social research methods: Qualitative and quantitative approaches (6th ed.). Boston: Pearson.

Pearce, P. (2005). Tourist behaviour: Themes and conceptual schemes. Clevedon, UK: Channel View Publications.

Quinn, R., Faerman, S., Thompson, M., McGrath, M., \& St. Clair, L. (2007). Becoming a master manager: A 
competing values approach (4th ed.). Hoboken, NJ: John Wiley \& Sons.

Robbins, S., Judge, T., Millett, B., \& Waters-Marsh, T. (2008). Organisational behavior (5th ed.). Frenchs Forest, Australia: Pearson Education Australia.

Samdahl, D., \& Jekubovich, N. (1997). A critique of leisure constraints: Comparative analyses and understandings. Journal of Leisure Research, 29(4), 430-452.

Scott, D., \& Jackson, E. (1996). Factors that limit and strategies that might encourage people's use of public parks. Journal of Park and Recreation Administration, 14(1), $1-17$.

Stebbins, R. (1982). Serious leisure: A conceptual statement. Pacific Sociological Review, 25(2), 251-272.

Stebbins, R. (2001). New directions in the theory and research of serious leisure. Lewiston, NY: Edwin Mellen Press.
USM Events. (2010). About 2011 Noosa Triathlon entry. Retrieved November 5, 2010, from http://www.usm events.com.au/Triathlon__Multi_Sport/Noosa_Triath lon_Multi_Sport_Festival/2011_Entry.htm

Veal, A. (2006). Research methods for leisure and tourism (3rd ed.). Harlow, UK: Prentice Hall.

Wilson, E., \& Little, D. (2005). A "relative escape"? The impact of constraints on women who travel solo. Tourism Review International, 9(2), 155-175.

World Triathlon Corporation. (2010). Ironman Australia general entry sold out. Retrieved November 5, 2010, from http://ironman.com/events/ironman/australia/recordbreaking-sell-out-for-26th-edition-of-australian-event\# axzz14MYYtkGj 